Volume 4, Number 2, 2018

\title{
Genetic Algorithm Application for Synthesis and Analysis of Electromechanical Systems
}

\author{
Bohdan Kopchak, Lidiya Kasha* \\ Lviv Polytechnic National University, 12 S. Bandera St., Lviv, 79013, Ukraine
}

Received: October 30, 2018. Revised: November 14, 2018. Accepted: December 07, 2018.

(c) 2018 The Authors. Published by Lviv Polytechnic National University.

\begin{abstract}
One of modern possible problem solutions of analysis and synthesis in electromechanical systems is the recourse to a genetic algorithm as a method of artificial intelligence. The originality of the proposed approach lies in the usage of fractional order models to solve the above-mentioned problem. The quality function is proposed to be used in the developed algorithms for analysis and synthesis procedures of electromechanical systems. It is also proposed to get the desired outcome of results deviation from the set values by means of quality function control after each iteration. Application of genetic algorithm method with the usage of fractional order reference models is an effective means of electromechanical systems transition processes approximation by fractional models as well as the selection of parameters of fractional controllers during their synthesis.
\end{abstract}

Keywords: electromechanical system; genetic algorithm; approximation; synthesis; $\mathrm{PI}^{\lambda} \mathrm{D}^{\mu}$-controller; model of fractional order model.

\section{Introduction and problems, which are appeared}

The modern tendency in the analysis and design of complex electromechanical systems (EMS) is the application of fractional order transfer functions for their description and intellectual methods of optimization. These complex systems include EMS with the following features of their control objects (CO): double mass, impact, backlash, viscous friction, nonlinear load, etc., which often leads to their description of high-order transfer functions (TF).

The analysis and synthesis of such systems by classical approaches is often complicated or leads to significant errors due to accepted assumptions. This forces researchers to improve new methods and tool including such intelligence methods of optimization as a genetic algorithm in solving the problems of the analysis and synthesis of such EMS. An increase in the number of publications on this subject [1-6] indicates a significant interest in such a problem. The genetic algorithm (GA) is designed to find the maximum of complex functions.

Due to the fact that the search space in the optimization problems is practically unlimited, in practice we use a solution that satisfies the meaning of the task to a satisfactory degree [7]. Together with Fuzzy Logic Toolbox and Neural Network Toolbox, implemented in MATLAB, GA is an effective tool for solving many "intellectual tasks". With all the diversity of publications, there are a number of unresolved issues related to the solution of the problems of analysis and synthesis of EMS, described by high order TF, which makes such studies relevant [7].

The purpose of this work is to develop a method for solving the problems of the analysis and synthesis of electromechanical systems described by high-order TFs, using the genetic algorithm method for the use of the models and controllers of the fractional order.

\footnotetext{
" Corresponding author. Email address: kashalidiya@gmail.com
}

This paper should be cited as: B. Kopchak, L. Kasha. Genetic algorithm application for synthesis and analysis of electromechanical systems. Energy Eng. Control Syst., 2018, Vol. 4, No. 2, pp. 73 - 78. https://doi.org/10.23939/jeecs2018.02.073 


\section{Addressing the problem and discussion of the research results}

Based on the analysis of reference sources, it is established that up-to-date and unresolved problems related to fractional calculations and its application should include the development of structural and parametric identification methods for complex EMS. In [8], research was carried out in the direction of developing the theory of the creation of fractional order models for the approximation of high-order PF EMS found based on identification of real objects of EMS. These studies were carried out using the particle swarm optimization method.

In the course of the research, it was established that the use of more complex TF fractional order for the approximation of integer TFs of high order requires an increase in the size of the swarm and, accordingly, the calculation time. At that stage, it became interesting to apply the method of the genetic algorithm to the solution of this class of tasks.

The genetic algorithm belongs to the class of stochastic and, as well as other algorithms of this group, it is focused on finding a quasi-optimal solution in the conditions of impossibility of full-fledged variants. Therefore, it is expedient to investigate the possibility of its use for the analysis and synthesis of EMS with the fractional order controllers. GA is different from other random-search algorithms; in particular, the author shows the particle swarm optimization method (PSO), which efficiency for solving similar problems is shown in [9].

The approximation procedure of the EMS' control object with GA application is as follows. The recorded transient process of the control object $y_{o \kappa}(t)$ is compared with the transient process of a particular fractional order model $y(t)$, which corresponds to the current parameters. The difference between the instantaneous values of these two transients in the discrete time moments is analysed by the error estimation unit and, through the block GA, corrects the parameters of the fractional model of the control object. When the given accuracy of approximation was reach, the block formation of the fractional pattern fixes its parameters.

There were cases of application of the genetic code (algorithm) (GA) as a universal method of optimization for the controller parameters correction. [3,7], show that GA is effective in optimizing the controller parameters (including neural and fuzzy ones). The author proposes to use an etalon model whose dynamic characteristic describes the desired reaction of the control object $y(t)$ to any input $x(t)$ with a certain accuracy. This etalon model is a simpler then real object and a dynamic section has low order [9].

The fractional order models, in this regard, have a significant advantage over the integers [9], because they provide high accuracy of approximation of real objects of control. Therefore, the possibility of using such models by the GA method for the EMS synthesis in the cases of representation of the control object by fractional and integer models, for the use of $\mathrm{PI}^{\lambda} \mathrm{D}^{\mu}$-controller of the fractional order is an interesting subject for research.

By this method, optional variants of controller factors were coded by chromosomes. In case when fractional $\mathrm{PI}^{\lambda} \mathrm{D}^{\mu}$-controller was used, this one is shown as Riemann's form (integral part) and Riemann-Liouville (differential part) as equation

$$
y(t)=k_{p} e(t)+k_{i} \frac{1}{\Gamma(\lambda)} \int_{0}^{t}(t-\tau)^{\lambda-1} e(\tau) d \tau+k_{d} \frac{1}{\Gamma(n-\mu)}\left(\frac{d}{d t}\right)^{n} \int_{0}^{t} \frac{e(\tau) d \tau}{(t-\tau)^{\mu-n+1}},
$$

were $k_{p}$ - proportionality factor; $k_{i}=1 / T_{i}$ - inversely proportional factor of integral time constant; $T_{i} ; k_{d}=T_{d}$ factor, which equal differential time constant $T_{d} ; \lambda$ - fractional orders; $\mu$ - of integral and differential components, correspondingly; $\tau=0, \Delta \tau \mathrm{K}, t-\Delta \tau, t, e(\tau)=e\left(t_{0}\right), e\left(t_{1}\right), \mathrm{K}, e(t)$.

Factors $k_{p}, k_{i}, k_{d}, \lambda, \mu$ can be selected from synthesis processes of fractional $\mathrm{PI}^{\lambda} \mathrm{D}^{\mu}$-controller and in case of using genetic algorithm, are described as shown in Fig.1.

\begin{tabular}{|c|c|c|c|c|}
\hline$k_{p}$ & $k_{i}$ & $\lambda$ & $k_{d}$ & $\mu$ \\
\hline Gene 1 & Gene 2 & Gene 3 & Gene 4 & Gene 5 \\
\hline
\end{tabular}

Fig.1. Chromosome form of $\mathrm{PI}^{\lambda} \mathrm{D}^{\mu}$-controller with fractional order adjusting. 
In case of integral PID-controller, synthesis or simple variants of fractional $\mathrm{PI}^{\lambda} \mathrm{D}^{\mu}$-controller $\left(\mathrm{PI}^{\lambda}, \mathrm{PD}^{\mu}\right)$ chromosome have only three gens.

For example, the approximation of the control object, which is described by the transfer function (TF) high fractional order, is carried out on the example of the TF $30 \mathrm{~kW}$ induction generator (IG) with self-excitation, obtained using the Mathcad and MATLAB Simulink software environments.

According to the results of experimental research, according to which TF of IG in the channel of excitation current $\mathrm{W}_{\mathrm{AG}}(\mathrm{s})$ is as follows [8]:

$$
W_{I G}(s)=\frac{U(s)}{I_{\text {ext }}(s)}=\frac{83 s^{3}+4851 s^{2}+59929 s+101674}{105 s^{3}+2934 s^{2}+15878 s+19395} .
$$

Transient process obtained in MATLAB Simulink, for TF (2) (curve "1") is shown in Fig.3.

First order fractional model [6] with $\mathrm{TF}$ is used for approximation $\mathrm{TF}$ of $\mathrm{IG}_{\mathrm{IG}}(\mathrm{s})$ (2) using genetic algorithm

$$
W(s)=\frac{k}{a_{1} s^{\alpha_{1}}+1} .
$$

Such problem of approximation can be solved by genetic algorithm in optimization package - Optimization Tool and MATLAB Simulink. In this package, we realize program by means of which we can compare transient process which corresponds to TF (2) with transient process of fractional order model with TF (3). We assess the results of comparing two transient processes on each iteration using quality function $(\mathrm{J})$

$$
J=\sum_{i=1}^{n}\left|y_{\text {i.ок. }}-\mathrm{y}_{\mathrm{i} .}\right|
$$

where $y_{\text {i.ок. }}-i$-est point of transient process of object control; $y_{i}-i$-est point of transient process of fractional order model.

The dependence of the quality functions $J$ on approximation according to TF (3) is shown in Fig.2.

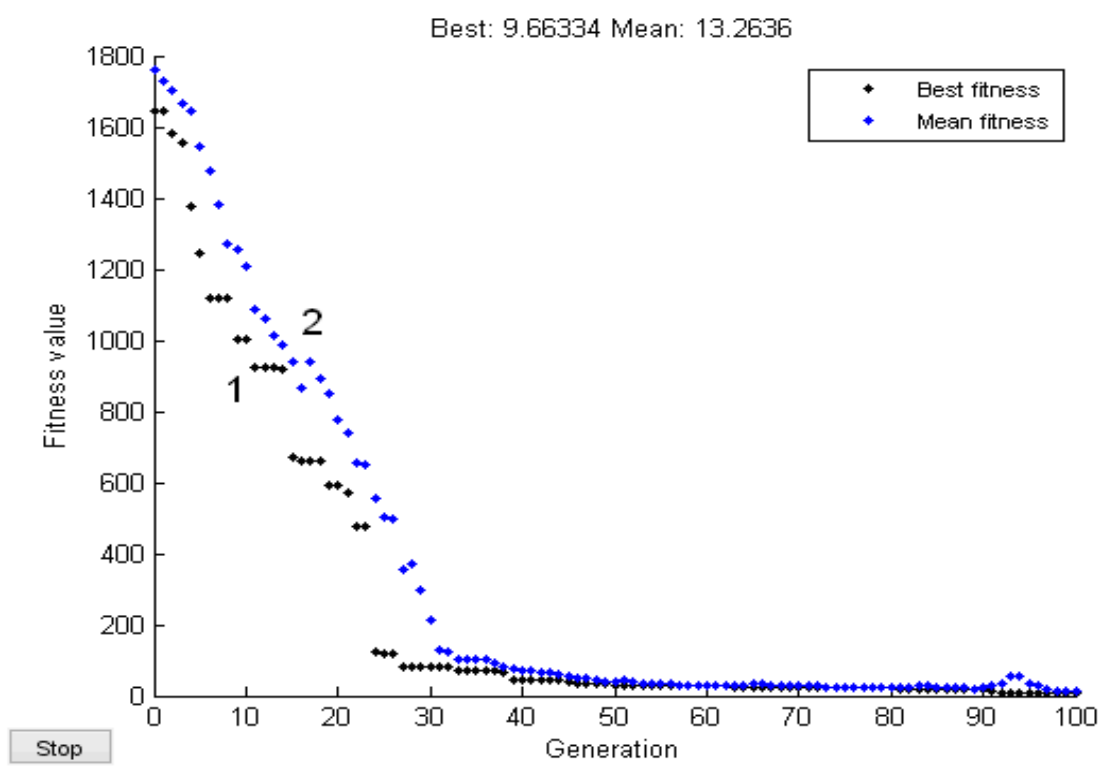

Fig.2. The dependence of the quality function on the iteration number for approximation: curve 1 - the best value for the quality function (Best), curve 2 - mean (Mean).

Fractional model, which was received after approximation process with genetic algorithm, is described as

$$
W(s)=\frac{5.317}{0.232 s^{0.892}+1} .
$$

The result was estimated by absolute root-mean-square deviation $\sigma[6], \sigma=0.0949$ and such deviation is admissible. Transient processes of fractional order model with TF (5), obtained by approximation, is given in Fig.3. 


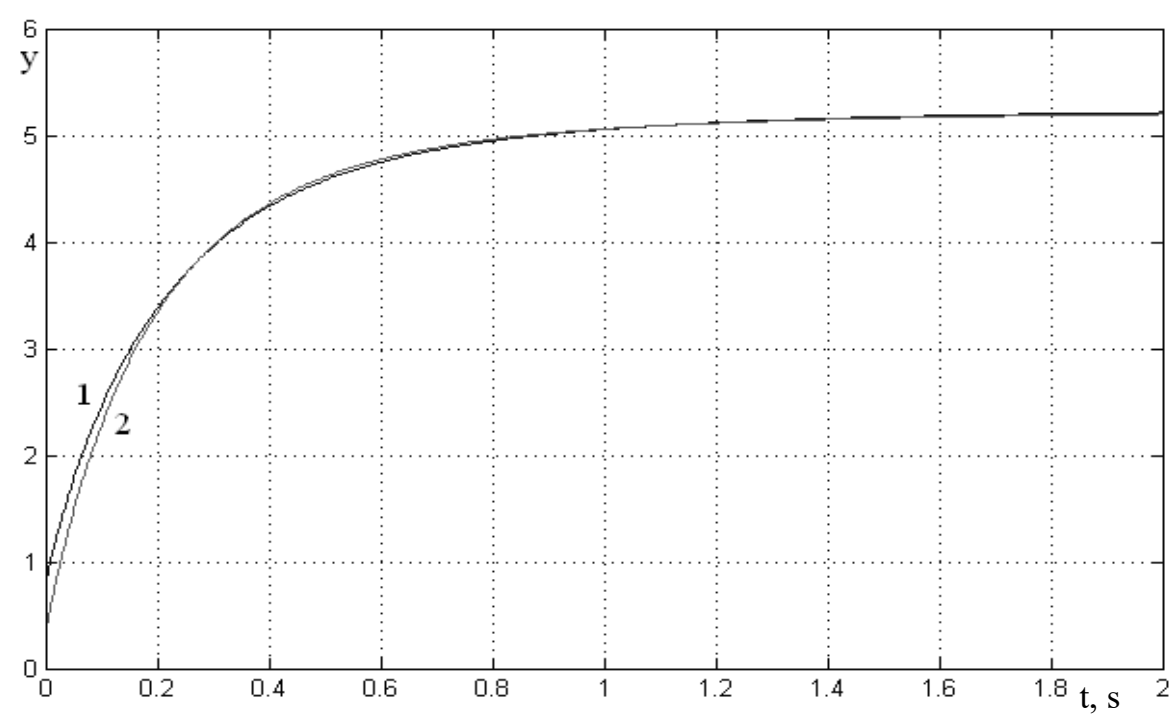

Fig.3. Transient functions of induction generator in keeping with: TF (2) - curve 1, TF (5) - curve 2.

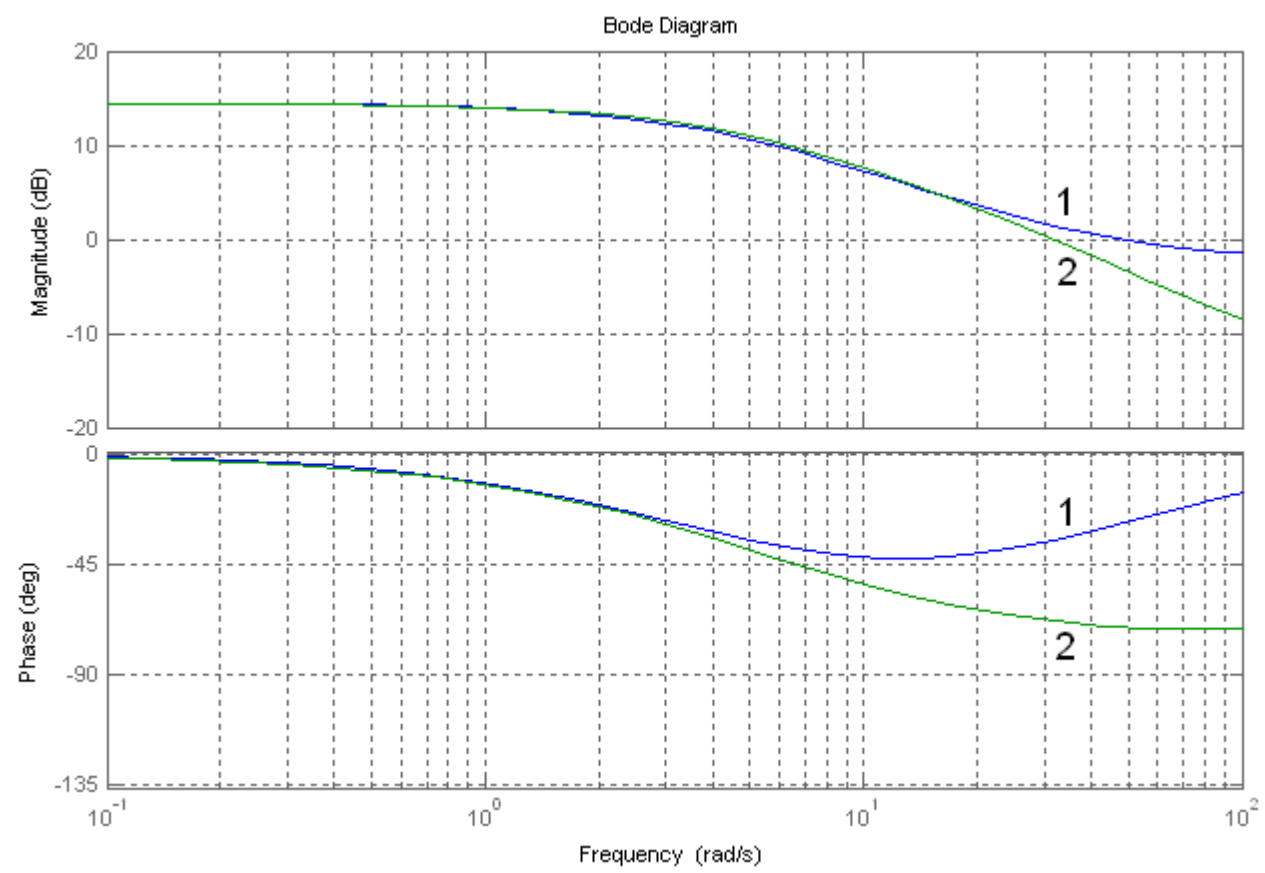

Fig. 4. Bode' diagrams for TF of IG $\mathrm{W}_{\mathrm{IG} . \mathrm{E}}(\mathrm{s})$ in excitation current channel, which are calculated TF IG (2) - curve 1 and by TF IG (5) - curve 2 .

The first-order fractional model of TF (3) among other fractional order models is chosen because it provides a sufficiently high accuracy of approximation and simplifies further synthesis of the fractional $\mathrm{PI}^{\lambda} \mathrm{D}^{\mu}$-controller, by reducing the order of the model. Now, we carry out synthesis of fractional $\mathrm{PI}^{\lambda} \mathrm{D}^{\mu}$-controller using genetic algorithm for control object with TF

$$
W(s)=\frac{1}{0.8 s^{2.2}+0.5 s^{0.9}+1}
$$

and fractional desired form with TF is chosen as a model [3]

$$
W_{\text {desired }}(s)=\frac{\omega_{o c}}{s^{1.2}+\omega_{o c}}
$$

with desired quality of transient process for $\omega_{o c}=10 \mathrm{~s}^{-1}: \mathrm{t}_{095}=0.29 \mathrm{~s} ., \delta=7.32 \%, \mathrm{t}_{\max }=0.52 \mathrm{~s}$. 
This quality of transient process corresponds to a technical optimum (TO) in EMS. In software MATLAB, we implemented program for application in genetic algorithm which calculates controller parameters by means of comparison of transient function of desired standard form (6) with transient function of locked circuit, with connected control object (6) and $\mathrm{PI}^{\lambda} \mathrm{D}^{\mu}$ - controller. Optimization app "Optimization Tool" with control over dependence of quality function $(\mathrm{J})$ on iteration number is applied to do this (4) while the final result estimation is based on the absolute mean square deviation $\sigma[3]$.

Approximation process which us taking place during synthesis of $\mathrm{PI}^{\lambda} \mathrm{D}^{\mu}$-controller parameters based on the model with desired quality of transient process is shown in Fig.5. Here, GA is usws as dependence of quality function on iteration number. By default, population totals 20.

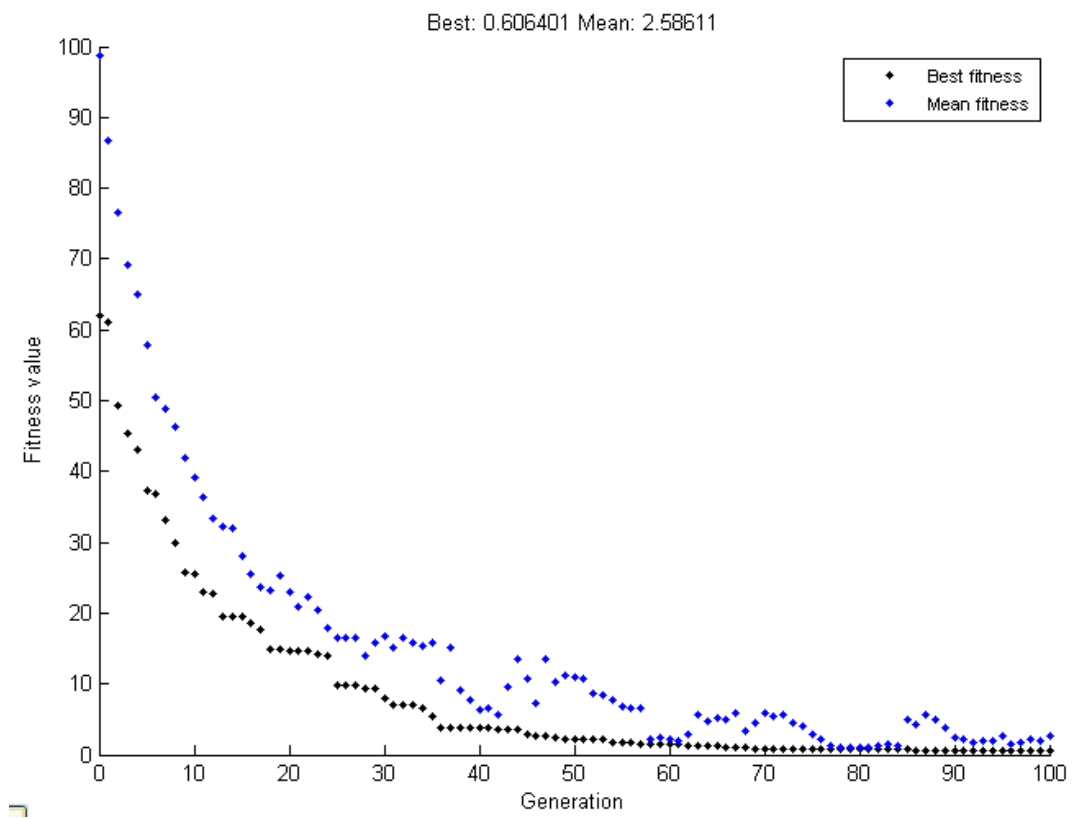

Fig. 5. Approximation process during synthesis of $\mathrm{PI}^{\lambda} \mathrm{D}^{\mu}$-controller factors for model with the desired quality of transient process.

At the end of the optimization process when using GA, we received fractional order $\mathrm{PI}^{\lambda} \mathrm{D}^{\mu}$-controller with a transfer function (8) and all functions visualisations are given in Fig.6.

$$
W_{p}(s)=6.844+10.567 s^{-1.357}+6.407 s^{1.073}
$$

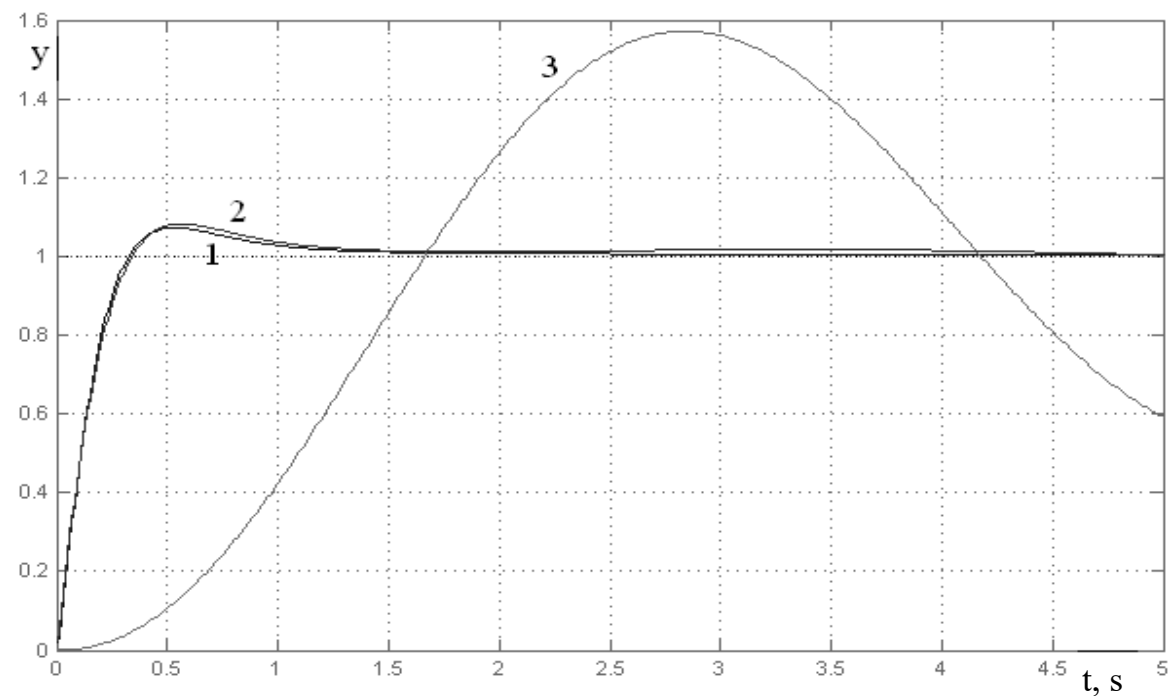

Fig. 6. Transient functions of fractional desired form with TF (7) - curve 1, optimized circuit - curve 2, controlled object curve 3 . 
Transient functions of optimized circuit with controller with synthesis by TF (8) - curve "2", control object with $\mathrm{TF}(6)$ - curve "3" are given in fig.6. Root square deviation $\sigma=0.0095$.

\title{
3. Conclusion
}

The application of the genetic algorithm method for the application of reference model of a fractional order is an effective method of electromechanical systems approximation by fractional ordering models and selecting parameters of the fractional order controller through their synthesis.

The use of reference models of fractional order is an effective means of approximating electromechanical systems by fractional ordering models and selecting the parameters of the fractional order controllers in their synthesis. The relative mean square deviation of the analysis and synthesis results from the given etalon models does not exceed $5 \%$.

\section{References}

[1] Hall, M.A. (2012) Cumulative multi-niching genetic algorithm for multimodal function optimization. International Journal of Advanced Research in Artificial Intelligence, vol. 1, no. 9, pp. 6-13. https://doi.org/10.14569/IJARAI.2012.010902

[2] Malhotra, R., Singh, N., Singh, Y. (2011) Genetic algorithms: concepts, design for optimization of process controllers. Computer and Information Science, vol.4, no. 2, pp. 39-54. https://doi.org/10.5539/cis.v4n2p39

[3] O. Lozynskyy, A. Lozynskyy, Y. Marushchak, B. Kopchak, P. Kalenyuk, Y. Paranchuk. Synthesis and research of electromechanical systems described by fractional order transfer functions. Modern electrotechnical and electrical systems: proceedings of SC MEES-2017, Kremenchuk, Nov. 15-17, 2017, pp. 16-19. https://doi.org/10.1109/MEES.2017.8248877

[4] B. Kopchak, M. Kopchak. Application of fractional order transfer function with zero and pole in approximation of electromechanical systems high order objects. Proceedings of XIVth International Conference: Perspective technologies and methods in MEMS design (MEMSTECH), Polyana, April 18-22, 2018,pp. 23-27. https://doi.org/10.1109/MEMSTECH.2018.8365694

[5] B. Kopchak. Approximation accuracy of electromechanical systems high order objects using different types of fractional order transfer functions. Proceedings of XIIIth International Conference: Perspective technologies and methods in MEMS design (MEMSTECH), Polyana, April 20-23, 2017, pp. 105-109. https://doi.org/10.1109/MEMSTECH.2017.7937544

[6] Fortuna, L., Graziani, S., Muscato, G., Nunnari, G., and Porto, D. Approximation of high-order lumped systems by using non-integer order transfer functions. Proceedings of the 7th Mediterranean Conference on Control and Automation (MED99), June 28-30, 1999, Haifa, Israel, 1999, pp. 2222-2230.

[7] Burakov, M.V. (2008) Genetic algorithm: theory and practice. $S P b . G U A P, 164$ p. (in Russian)

[8] Kopchak, B. (2014) Approximation accuracy analysis of high order electromechanical systems objects with fractional transfer functions of different types. Proc. of Lviv Polytechnic National University: Electric Power and Electromechanical Systems, No. 785, pp. 33-38. (in Ukrainian)

[9] Kopchak, B. (2014) Approximation of transition functions by fractional order polynomials. Electrotechnic and Computer Systems, vol. 14, no. 90, pp. 20-27. https://doi.org/10.15276/etks.14.90.2014.05 (in Ukrainian)

\section{Застосування методу генетичного алгоритму для аналізу і синтезу електромеханічних систем}

\author{
Богдан Копчак, Лідія Каша \\ Національний університет «Львівська політехніка», вул. С. Бандери, 12, м. Львів, 79013, Україна
}

\section{Анотація}

Один із методів вирішення задач аналізу та синтезу електромеханічних систем (ЕМС) є використання підходів штучного інтелекту, а саме методу генетичного алгоритму (ГА). Оригінальність описаного у статті підходу полягає у застосуванні моделей дробового порядку для вирішення такого роду задач. В розроблених алгоритмах процедур аналізу та синтезу ЕMC запропоновано використовувати функцію якості, та, контролюючи результат після кожної ітерації, отримувати бажане значення відхилення результатів. Застосування методу ГА при використання моделей дробового порядку є ефективним засобом апроксимації перехідних процесів ЕМС дробовими моделями та вибору параметрів дробових регуляторів.

Ключові слова: параметри регуляторів; генетичний алгоритм; апроксимація; синтез; ПІ ${ }^{\lambda}{ }^{\mu}$-регулятор; моделі дробового порядку. 